\title{
NOTAS SOBRE PAISAGEM E ENSINO DE PAISAGISMO
}

\section{NOTES ON LANDSCAPE AND LANDSCAPE TEACHING}

\author{
Vladimir Bartalini
}

\section{Resumo}

Assume-se, aqui, que o objeto do ensino de paisagismo é a paisagem. Esta assunção, que pode parecer óbvia, é simples apenas na aparência. $\mathrm{Na}$ verdade, ela exige uma indagação sobre a paisagem, "objeto" fugidio por excelência. $\mathrm{O}$ que se tenta neste artigo são aproximações à ideia de paisagem que pressupõem, por um lado, os vínculos desta com a natureza da Terra e, por outro, sua tendência à "cosmicização". Busca-se, também, dissociar a paisagem da hegemonia, se não da exclusividade do sentido da visão, herdada do pensamento moderno. Por fim, pleiteiase a contribuição de diferentes formas de expressão ou de linguagens poéticas para embasar o ensino de paisagismo, uma vez que a mera capacitação técnica parece não dar conta da amplidão de sentidos que a paisagem acolhe.

Palavras-chave: Paisagem. Paisagismo. Ensino.

\section{AbstRact}

It is assumed here that the object of landscaping teaching is the landscape. This assumption, which may seem obvious, is simple only in appearance. In fact, it requires an inquiry into the landscape, a fugitive "object" par excellence. What is attempted in this article are approximations to the idea of landscape that presuppose, on the one hand, its links with the nature of the Earth and, on the other hand, its tendency towards "cosmicization". It also seeks to dissociate the landscape from hegemony, if not exclusivity, from the sense of vision inherited from modern thought. Finally, the contribution of different forms of expression, or of poetic languages, is used to support the teaching of landscaping, since mere technical training seems to fail to account for the wide range of meanings that the landscape receives.

Keywords: Landscape. Landscaping. Teaching. 


\section{INTRODUÇÃO}

Há tantos modos de enfocar o ensino de paisagismo quantas são as acepções de paisagem. Portanto, está aqui descartada a pretensão de contemplar as questões do ensino de paisagismo de um modo cabal. Trata-se, mais simplesmente, de considerar alguns pontos que vêm à tona quando se entende a paisagem não como "um círculo fechado, mas como um desdobramento", como algo que "só é verdadeiramente geográfico por seus prolongamentos, pelo plano de fundo real ou imaginário que o espaço abre para além do olhar" ou então, ainda com Dardel, como algo que "se unifica em torno de uma unidade afetiva dominante [...] que põe em questão a totalidade do ser humano, seus vínculos existenciais com a Terra, (numa) relação que afeta a carne e o sangue" (DARDEL, 1990, p. 42).

Obviamente, isso coloca desafios não só para o pensamento sobre a paisagem, mas também para o ensino do paisagismo. A paisagem é, em essência, aparência. É superfície que se apresenta diante de nós. Mas com seus véus ela se vela. Removendo-lhe os véus supõe-se desvelá-la por completo. No entanto, por ser Terra, ela se fecha e novamente se vela, recolhe-se, pede cuidados. Conhecer a paisagem e atuar na paisagem tem a ver, em parte, com revelação e, ao mesmo tempo, com um novo encobrimento: uma abertura e um fechamento. E se o verbo desvelar diz uma ação, ele diz também cuidar, uma relação ética: desvelo.

\section{Paisagem: Finitude Aberta}

As disciplinas de paisagismo nos cursos de graduação de arquitetura são, em geral, disciplinas de projeto, ou seja, supõem o controle e o direcionamento de energias - não é esse o sentido de disciplina? - para intervir no real, transformando-o. Isso implica método e técnica, o que significa, no senso comum, ter à disposição regras, normas, ferramentas e a habilidade de utilizá-las a serviço de uma finalidade, de um objetivo.

Ninguém duvida da importância do domínio dos campos metodológico e técnico para se realizar qualquer tarefa, qualquer proje- to, e que a transmissão e o desenvolvimento dos conhecimentos referentes a esses campos, mediante o exercício do projeto, estão na base do ensino acadêmico de arquitetura e de paisagismo.

É possível ter acesso, hoje, a um grande, diversificado e bem qualificado volume de informações sobre métodos e técnicas para amparar o ensino do paisagismo em cursos de graduação, o que, sem dúvida, contribui ou deveria contribuir para melhores resultados em termos de projeto e de execução de obras paisagísticas. Temos também um grande número de professores capacitados e de alunos interessados no campo do paisagismo. Contamos, por fim, com a disseminação crescente do interesse por assuntos referentes à paisagem em variados segmentos sociais e, por vezes, também com o comprometimento efetivo desses diversos segmentos com as questões que envolvem a paisagem nos seus ambientes cotidianos, independente da sua condição de vida e da posição que ocupam na hierarquia social.

Tudo isso corrobora a importância de desenvolver e aprofundar o ensino de paisagismo nos cursos de graduação e significa também o aumento da nossa responsabilidade - como professores, pesquisadores e profissionais - na formação de futuros profissionais, professores e pesquisadores aptos a compreender as paisagens às quais são dirigidas suas atenções.

No entanto, apesar dessas condições favoráveis, corremos o risco - aliás, sempre correremos algum risco desde que nos mantenhamos vivos - de atingir um alto desempenho, de sermos cada vez mais eficientes no alcance dos nossos objetivos, de atendermos às agendas ambientais e sociais e, ainda assim, deixarmos escapar a paisagem entre os dedos.

Coloca-se, então, um primeiro ponto que merece ser abordado ao se tratar dos desafios que o ensino de paisagismo nos impõe. Ele se refere ao próprio objeto em torno do qual esse ensino gravita: a paisagem.

Embora na cultura ocidental, notadamente a partir do início da Era Moderna, o sentimento e a noção de paisagem estejam fortemente associados à percepção estética da natureza sob o comando da visão, as questões que a paisagem nos propõe não se 
limitam à mera visibilidade. Tampouco serviria apoiar-nos apressadamente na assertiva de Dardel- "a paisagem não é feita, em sua essência, para ser vista, mas inserção do homem no mundo, lugar de um combate pela vida, manifestação do seu ser com os outros, base do seu ser social" (DARDEL, 1990, p. 44)- para imputarmos, indiscriminadamente, tudo o que existe à paisagem ou confundi-la com a própria realidade geográfica. Por sinal, o mesmo Dardel, referindo-se ao depoimento do soldado Lintier que, em 1915, entrincheirado no campo de batalha, admirava a manhã invernal com os ohos de quem poderia não vê-la mais daí a poucos minutos, afirma: "Ali onde a Terra é aquilo que se pode perder de um instante para outro, ela retoma todo seu frescor de espetáculo único e novo" (DARDEL, 1990, p. 50, grifo nosso). E, algumas páginas adiante, Dardel ainda volta a nos dizer que "O que o homem procura na Terra é um 'rosto', um certo acolhimento" (DARDEL, 1990, p. 60).

A paisagem pode não ser feita, em sua essência, para ser olhada, mas quem emprega palavras comorosto, fisionomia e espetáculo para referir-se a ela está usando termos relacionados à visão. Um rosto só é rosto porque é visto. E o rosto só é visto quando se está fora do corpo, por aquele que vê o rosto de um outro ou o próprio rosto refletido, circunstância em que já se é um outro. Não há, então, porque não inverter o sentido da frase de Dardel e dizer que a essência da paisagem é ser vista. Ela só existe porque é vista, porque nela alguém reconhece um rosto e prova algum sentimento ao reconhecê-lo.O importante a considerar é que tal reconhecimento não se esgota na visão.

Há, na paisagem, algo que a supera e que não se vê, algo que indagamos e que nos indaga. O horizonte, ao definir um aqui e um além, é constitutivo da paisagem. A paisagem pressupõe um horizonte, mas ele se desloca à medidaem que nos deslocamos. Nunca o atingimos. Queremos exprimir este excesso, que é essencial e constitutivo da paisagem, mas o inefável resiste à linguagem e não há fómulas para satisfazer a essa vontade ou necessidade de expressão. Se a paisagem for reduzida à sua mera objetividade, estaremos então ainda mais longe de atingir tal intento. Além do mais, casoexistam respostas afirmativas que nos aproximem da meta, provavelmente elas não residirão em nenhum endereço fixo.

A presença dessa dimensão fugidia e, ao mesmo tempo, tão fundamental é reconhecida em diferentes culturas, mesmo entre aquelas que não possuiam um nome específico para se referir à paisagem. Pressentiam-na os yorubá, que a expressaram num dos mitos mais significativos e inspiradores para nós, paisagistas: o de Euá, a orixá do horizonte, do encontro do céucom a terra, do céucom o mar. Euá, filha de Nanã, era calada e solitária: queria viver sozinha, dedicada à tarefa de afastar o sol e fazer a noite descer no horizonte. Nanã, preocupada, insistia em casar a filha. Euá, para fugir dosarranjos matrimoniais tramados pela mãe, pediu socorro a seu irmão, Oxumaré, orixá do arco-íris, que a levou consigo para trás do horizonte, onde passaram a viver juntos, inatingíveis (PRANDI, 2008, p. 238-239).

A presença constante, real e, no entanto, inalcançável do horizonte é um traço distintivo da paisagem, a qual é sempre circunscrita e, ao mesmo tempo, aberta a algo que a ultrapassa. Mesmo sendo esta uma dimensão essencial da paisagem, é claro que ela não basta para defini-la, aliás, seria inócuo e até empobrecedor tentar uma definição, mas também não nos interessam, aqui, os enfoques que, ao diluírem a noção de paisagem, esvaziam a questão, ou seja, anulam a especificidade da paisagem por passarem ao largo dela, como ocorre com esta definição de Gilles Clément, um dos nomes mais proeminentes do paisagismo contemporâneo, tanto por sua atividade profissional quanto por suas reflexões teóricas:

Paisagem[...] designa aquilo que está diante do nosso olhar. [...] À questão: "o que é a paisagem?" podemos responder: é aquilo que guardamos na memória depois que deixamos de olhar; é aquilo que guardamos na memória quando os nossos sentidos deixam de ser exercidos dentro de um espaço investido pelo corpo. Não há escala na paisagem, ela pode se dar no imenso e no minúsculo, ela vale para todas as matérias - vivas ou inertes -, para todos os lugares, 
ilimitados ou privados de horizonte: podemos falar de paisagem aqui mesmo [...], nesta sala [...] (CLÉMENT, 2012, p. 19-20).

Até a penúltima linha, as considerações de Clément são pertinentes ao que se pretende abordar aqui; porém, quando ele dispensa o horizonte e admite falar de paisagem mesmo no interior de um recinto, nos afastamos bastante dele. Interessam-nos, antes, as abordagens que admitem e vasculham as peculiaridades da paisagem, distinguindo-a, por exemplo, de ambiente e de território, como faz Rosario Assunto, que entende a paisagem como "a 'forma' na qual se exprime a unidade sintética a priori da 'matéria (território)' e do 'conteúdo-ou-função (ambiente)'" (ASSUNTO, 2011, p. 128). O mesmo autor já se ocupara, anteriormente, em esclarecer as diferenças entre paisagem e espaço (ASSUNTO, 2005, p. 13-26). Para ele, a paisagem é espaço e não objeto no espaço, e mais, toda paisagem é espaço, mas nem todo espaço é paisagem. "A paisagem é o próprio espaço que se constitui em objeto de experiência estética, sujeito de juízo estético" (ASSUNTO, 2006, p. 16). No entanto, prossegue Assunto, embora uma praça, um salão, ou mesmo a abóbada celeste, por exemplo, possam ser espaços sujeitos a juízo estético, eles não são paisagens, ou por serem fechados ou por serem ilimitados. A paisagem é delimitada, mas não fechada, abre-se ao ilimitado, mas não é infinita. A paisagem é limitada e aberta, é "finitude aberta" por abrir-se ao céu, ao infinito, "assim como o infinito, passando pela finitude (paisagem), é infinitude limitada" (ASSUNTO, 2005, p. 19).

Jean-Marc Besse, ao comentar a relação entre paisagem e infinito, toca no ponto nevrálgico: "talvez [...] esta presença transbordante do infinito no finito seja a força mais íntima da experiência paisagística" (BESSE, 2006, p. 8).

Se essa presença transbordante do infinito no finito é constitutiva da paisagem, vale questionar se a paisagem seria propriamente uma "invenção" da modernidade - o que já nos predisporia a manuseá-la à vontade, sem o devido respeito -ou se, ao contrário, ela já não existiria desde que o homem se pôs a observar a natureza, ou seja, desde que começou a tomar contato com as coisas, portanto, desde sempre e não somente a partir da Era
Moderna. E desde que o homem se viu como um ser entre outros seres, sobre a terra e sob o céu, e fez a distinção entre o espaço que lhe é próximo, familiar, e aquele que lhe é distante e incógnito e se reconheceu como mortal, finito perante um temposeja cíclico seja linear - que ultrapassa a sua existência, o homem não deixou de se deparar com o infinito, mesmo que não o tenha formulado conceitualmente. Nem de olhar com estranhamento e admiração o que se lhe apresenta como o outro ou o desconhecido, seja este outro o próprio homem seja a natureza em geral.

A paisagem, ou melhor, a "vocação paisagística" - recorrendo a uma adaptação das reflexões de Octavio Paz sobre poema e poesia para a paisagem -, esse modo de delimitar a natureza como finitude que, por ser aberta, é invadida pelo infinito ou, ainda, esse modo de ver a natureza como algo que cresce, nas palavras de Rilke, "em direção a um futuro que nós não viveremos" (RILKE, 2009, p. 59), como um outro absoluto que nos faz sentir estranhos e assustadoramente sós, essa noção de paisagem existiria desde sempre: "começou com os primeiros homens e [...] só acabará quando nossa espécie emudecer" (PAZ, 2012, p. 13) ou, ampliando a paráfrase, quando nossa espécie não souber mais exprimir o que sente.

É possível ir mais além na argumentação de que a sensibilidade paisagística e a dimensão, digamos, cósmica da paisagem são inerentes ao homem, à sua geograficidade, para usar o termo cunhado por Dardel, e que, portanto, a noção de paisagem antecede o advento da Modernidade. A rigor, o que se pode imputar à chamada civilização ocidental é o pensamento sobre a paisagem, ou seja, usando as palavras de Augustin Berque, "um pensamento que tem a paisagem como objeto" (BERQUE, 2008, p. 9, grifo nosso), o que exige uma operação de representação. Mas a sensibilidade paisagística e os vínculos da paisagem com o infinito, ou com uma ordem cósmica, podem ser detectados antes do Renascimento e em culturas que não as europeias.

Ainda no século I da nossa era, as cartas de Plínio, o Jovem, registraram as amenidades de suas ville, uma delas conhecida como Laurentina, situada numa "costa maravilhosamente diversificada pelas ville ali distribuídas, de forma agrupadaoui- 
solada" (PLÍNIO, 1995, p. 132). Também referindo-se à villa Laurentina, escreve Plínio:

Converso só comigo e com meus livros. Oh que vida reta e sincera, oh que otium doce e honesto, e direi quase mais belo do que todo o negotium. Oh mar, oh praia, oh verdadeiro e secreto templo das Musas, quantas coisas descobris, quantas me inspirais! (PEREIRA, 2006, p. 85).

A fruição da beira-mar (CORBIN, 1989) a partir do século XVIII seria, então, antes uma redescoberta do que propriamente o nascimento de um novo tipo de paisagem.

A paisagem ("templo das Musas") como provedora de condições propícias ao saber ("quantas coisas descobris"), ao influxo anímico ("quantas me inspirais"), enfim, à experiência contemplativa, tomará (ou retomará), a partir de meados do século XV, pleno vigor nos jardins das ville italianas renascentistas, espelhados, justamente, nas descrições de Plínio.

Bartolomeu Taegio, em seus diálogos sobre a villa, de 1559, expressa-se em termos que relembram os de Plínio, ao falar do sentimento de "grande alegria e (de) felicidade humana" proveniente da contemplação, na qual se fundema atividade da leitura, com o conhecimento da natureza nela implicado, e a fruição da paisagem:

Estando na villa sozinho em meu abrigo, [...] só com a alma, sem mexer qualquer parte do corpo, imagino todas as partes do Oceano, abraço toda esta bola redonda que se chama Terra, descubro quantos mares a inundam, quantos lagos a banham, quantas ilhas, portos, recifes, montanhas, planícies castelos, cidades, províncias e regiões nela existem [...]. E não contente com estas coisas baixas, alço voo nas asas do pensamento e, passando por todas as regiões do ar e da esfera do fogo, entro no céu e, deslizando pelo intelecto de esfera em esfera, e de uma inteligência à outra, conduzo-me enfim ao próprio Deus.
E depois, pleno de maravilhas, começo a retornar ordenadamente à consideração das coisas que Ele produziu; e subindo e descendo desta maneira atinjo o perfeito conhecimento deste mundo. Passo meus dias em grande alegria; a felicidade humana provém dessa contemplação (TAEGIO, 1559 apud BESSE, 2006, p. 29).

Outro humanista italiano contemporâneo de Taegio, Jacopo Bonfadio, ao descrever para um amigo o seu retiro à beira do lago de Garda, declara que seu humor melhora

pela simples visão deste lago e de sua praia [...]. Aqui o céu é aberto, de um brilho claro e de um vivo esplendor que, sorrindo, convida-nos à alegria. [...] Várias coisas podem ser vistas aqui, requerendo um olhar diligente e muita consideração. Assim, acontece que, não importa quantas vezes um homem retorne aqui, ele encontrará novas maravilhas e novos prazeres (BONFADIO, 1541 apud HUNT, 2000, p. 33).

Tudo o que Bonfadio aponta para ser apreciado pela visão, comenta John Dixon Hunt, é apenas um pretexto para se atingir, em meio às variações de formas e de aspectos, algo não visível e permanente. É no deslizar do material para o espiritual, ou seja, na passagem da primeira experiência sensível para a contemplação e, subsequentemente, no retorno à dimensão sensível do próprio sítio, que reside o "coração da experiência da paisagem" 1 .

Embora não seja necessário insistir no verdadeiro lugar comum de que a Antiguidade inspirou a cultura no início da Modernidade, vale ressaltar que tal influência estendeu-se não só à arte dos jardins mas, conforme visto, à própria paisagem enquanto recurso para atingir e usufruir um estado de harmonia com o Todo. A evocação, direta ou indireta, de Plínio e de Cícero, no que concerne a este atributo da paisagem por parte dos humanistas renascentis1 Para dizer isto, Bonfadio teria usado uma estratégia retórica na missiva:suas palavras não
bastam; é preciso que seu amigo vá ao local e veja o cenário com seus próprios olhos. Esta
interpretação, que Hunt expõe no corpo do texto do terceiro capítulo de Greater perfections, tem prosseguimento na nota seis do mesmo capítulo (HUNT, 2000, p. 33). 
tas, confirma tal vínculo, o que reforça a posição dos defensores da ideia de que a paisagem, para vir à luz no ocidente, não precisou esperar o século XV, quando se iniciou seu desenvolvimento como gênero autônomo de pintura e a palavra que a denomina foi incorporada ao vocabulário das línguas europeias².

Se, como visto, o trânsito contínuo e reversível do sensível terreno para o cósmico, propiciado pela paisagem, está na base da chamada cultura ocidental, tendo repontado no século XV, ele não deixa de se manifestar também fora dela. E não só na China que, sabidamente, é das mais antigas entre as civilizações paisagistas e na qual os valores estéticos e espirituais da paisagem estiveram desde sempre associados ${ }^{3}$, mas tambémna civilização asteca que, embora contemporânea à da Europa moderna, não tivera contato com estaaté o final do quatrocentos. Veja-se, de passagem, o seguinte relato sobre parques e jardins astecas, feito com base nas fontes bibliográficas disponíveis na Biblioteca de Estudos Pré-Colombianos, em Dumbarton Oaks, Estados Unidos:

2 Entre outros, Massimo Venturi Ferriolo defende a existência de uma sensibilidade para a paisagem já no mundo grego, ainda que não houvesse, então, uma palavra que lhe corres pondesse: "mesmo que a paisagem seja uma representação recente, a sua ideia é antiga e é ligada ao sentimento de admiração suscitado pela contemplação". (FERRIOLO, 2002, p. 19). Observa também as semelhanças histórico-sociais entre a palavra Landschaft, que remete à paisagem, e o termo Land, este já presente no alto alemão do século IX, anteriormente, portanto, à de que a paisagem tenha sido uma invenção da Modernidade.

3 O pioneirismo da China em relação à paisagem é defendido por Augustin Berque, com base em critérios que levam em conta a existência de uma palavra para dizê-la, de uma literatura que a canta ou descreve, de pinturas que a representam e de jardins para apreciá-la(BERQUE, 1994, p.16,1995,2008, p. 69-81). Sobre a proeminência da paisagem na pintura chinesa, cf. Ryckmans(2010). "Sob os Song conclui-se a evolução que substituiu progressivamente os personagens pela paisagem como objeto privilegiado da criação pictórica. A distinção feita por Zhang Yanyuan subsiste em seu princípio - permanece a distinção entre tema superior capaz de exprimir o ritmo espiritual, e tema inferior, que apenas requer uma execurcão que se asseme à formas exteriores - mas ela muda de objeto: a categoria superior refo que exclusivamente à paisagem, exclusivami mais ao mesmo plano que as arquiteturas e os objetos inanimados. Isto expresso com muita clareza, por exemplo, no famoso texto de Su Dongpo [...], que estabelece a distinção entre a 'forma constante' e o 'princípio constante': personagens, animais, arquiteturas e objetos inanimados referem-se à ordem inferior da 'forma constante', cuja expressão está ao alcance de qualquer artesão consciencioso, capaz de reproduzir a evidência objetiva dos seus próprios sentidos. O 'princípio constante', ao contrário, engloba montanhas, pedras, bambus, árvores, águas, nuvens, isto é, todos os elementos da paisagem; para estes não existem arquétipos formais objetivos, sua essência é imponderável e só o letrado tem o privilégio de apreendê-la" (RYCKMANS, 2010, p.38-39).
Fora da cidade, os palácios eram construídos em locais notáveis pela sua beleza e pelo seu significado histórico e sagrado. Enquanto os jardins das cidades exibiam plantas e flores ornamentais e aromáticas em ambientes murados, os jardins no campo voltavam-se aos prazeres mais intelectuais da paisagem e à horticultura experimental; os governantes construíam palácios em bosques plantados ou em meio a viveiros de plantas, onde vegetais exóticos eram mantidos com esmero. A água, nestes lugares, não se limitava a tanques e canais, mas incluía fontes e quedas d’água cuidadosamente concebidas, verdadeiras celebrações da engenharia e da engenhosidade humanas, e os palácios campestres eram implantados para se apreciar o espetáculo dos canais de água abastecendo grandes extensões de terras irrigadas, ou cidades inteiras (EVANS, 2000, p. 206).

São exemplos o parque de Chapultepec, implantado em uma colina localizada a cerca deseisquilômetros a oeste do centro de Tenochtitlán (atual Cidade do México), e o parque Texcotzingo, também em uma colina, a leste da cidade de Texcoco ${ }^{4}$, e dela afastada por distância similar. Os centros de ambas as cidades, separados por aproximadamente trinta quilômetros, eram marcados por suas respectivas colinas artificiais em forma de pirâmide. Afora as qualidades inerentes a cada parque, das quais, atualmente, dão provas apenas as ruínas e os registros dos primeiros tempos da colonização espanhola, chamam a atenção o alinhamento e a simetria a que obedece sua distribuição: ao longo de um eixo dispõem-se, em uma das extremidades, o par

4 Quando da chegada dos europeus, no final do séçulo XV, as duas maiores cidades astecas eram Tenochtitlán e Texcoco, distantes cerca de trinta quilômetros uma da outra, implantadas em margens opostas do grande lago de Texcoco. As dinastias que as governavam, mantendo reç̃ do relaçoes de parentesco, beneficiaram-se grandemente da politica de tributos, o que lhe permitiu equipar não só as duas capitais e seus arredores imediatos, mas toda a bacia do México com parques de características distintas, de acordo com suas finalidades, classificados em quatro tipos: grandes retiros imperiais, parques recreativos urbanos, jardins hortícolas e reservas florestais de caça. No período de apogeu de Tenochtitlán e Texcoco, ca. 1430 e 1520, os membros da realeza asteca valorizavam e reivindicavam esses lugares carregados de significado e favorecidos por vistas magníficas, dedicados tanto ao deleite dos sentidos quanto às finalidades rituais e contemplativas, e neles intervinham empregando recursos da arquitetura, daescultura e do que, posteriormente, se enfeixaria no termo paisagismo (EVANS, 2000). 
Chapultepec e Tenochtitlán, e na outra, o par Texcoco e Texcotzingo. Sabendo-se que a dualidade é "um dos princípios básicos e estruturadores do pensamento religioso mesoamericano [...] um reconhecimento da essencial interdependência dos opostos"(MILLER; TAUB, 1993, p. 81 apud EVANS, 2000, p. 213-214), é lícito reconhecer também entre os astecas sinais da correlação entre a fruição estética da paisagem e a contemplação de um princípio abstrato de ordenação universal.

Assim, a interlocução entre os planos sensível e mental (ou espiritual), entre o visível e o não visível, entre o real e o imaginário, entre o circunscrito e e o incomensurável, entre o aqui e o que se abre além do seu horizonte, todos esses vínculos da paisagem com o que a excede podem ser verificados em diferentes tempos e culturas, manifestando-se sob diversas formas.

Por mais distintas que sejam entre si, essas formas de expressão têm algo em comum: todas são linguagem, ou seja, "sistemas expressivos dotados de poder significativo e comunicativo. [...] Pintores, músicos, arquitetos, escultores e outros artistas não usam como materiais de composição elementos radicalmente diferentes dos que o poeta emprega. Suas linguagens são diferentes, mas são linguagens" (PAZ, 2012, p. 28). É pela forma de exprimir esses conteúdos, pela linguagem que se cria para expressá-los que o ensino de paisagismo poderia, primordialmente, se interessar.

\section{Poesia e téCnICA}

Algumas dificuldade então se apresentam, como aquela imposta pela usual oposição entre a dureza, o rigor, o constrangimento ou, numa palavra, a cientificidade dos métodos e das técnicas, de um lado e, de outro, a pressuposta liberdade que acompanha toda atividade criativa, tida como o lado suave, leve, indevidamente chamado poético, do processo de projetar. Supõe-se, às vezes, que dar um "toque poético" aos projetos, às intervenções paisagísticas conduziria ao equilíbrio pretendido, atenuando a aspereza da técnica, como um tempero que se adiciona a um prato para deixá-lo menos pesado ou insosso. Sim, a poesia é indispensável, mas se ela for entendida como complemento, es- taríamos repetindo aquilo que, por décadas, foi imputado ao paisagismo e contra o que já tanto se lutou e se continua a lutar: disfarçar, ou, na melhor das hipóteses, amenizar a dureza das intervenções, como se fosse uma licença a ser concedida apenas depois que os assuntos "sérios" já estivessem resolvidos. Além disso, um ingrediente que se adiciona à receita pode levar a resultados negativos mesmo a curto prazo: os temperos acabam por enjoar.

Para tecer num mesmo tear paisagem e poesia, até por conta do desgaste das palavras, é recomendável uma aproximação oblíqua (mas não dissimulada...) que evite pontificações e prescrições dogmáticas. Numa analogia aos procedimentos usados nas prospecções, convém avançar e aprofundar aos poucos, camada por camada, e contentar-se com os vislumbres, uma vez que não se há de chegar a um objeto acabado e passível de ser exposto integralmente à luz.

Justamente por ser aparência, a paisagem, assim como o poema para Octavio Paz (2012, p. 21), "é uma máscara que oculta o vazio, bela prova da supérflua grandeza de toda obra humana".

É claro que a adaptação desta sentença de Octavio Paz para a paisagem exige, como toda adaptação, algum reparo, um esclarecimento. No caso, o reparo é pequeno, mas não desprezível, e aplica-se ao complemento "obra humana", que arremata a sentença. Diz-se que a paisagem é invenção humana, com lugar e data de nascimento. Dizer que a paisagem é invenção já faz supô-la como artifício; daí para sua reificação e consequente destruição basta um passo. É preciso prevenir-se quanto a isso: os objetos (sejam eles naturais ou artificiais), os materiais e as cores presentes na paisagem, considerados isoladamente ou em conjunto, não constituem, por si sós, a paisagem. Se esta é invenção humana, ela o é não por conta da procedência natural ou artificial dos objetos, mas pelo sentido que o olhar e, mais amplamente, o fazer humano confere àquilo que sente e percebe.

Não se trata de priorizar a postura subjetivista que atribui ao sujeito o comando da operação na constituição da paisagem, que entende esta como representação ou a vê como uma projeção do sujeito. Tampouco a objetivista, que admite a persistência da pai- 
sagem mesmo quando cessa o olhar humano. As coisas chegam aos nossos olhos do mesmo modo e ao mesmo tempo em que os nossos olhos chegam às coisas.

Não haveria, assim, conforme nos diz Wunenburger ao tratar da poética ecológica esboçada por Bachelard, uma assimilação ou digestão da paisagem por parte do sujeito (o exterior introjetado no interior), nem uma adaptação da paisagem ao sujeito (o interior dominando o exterior para submetê-lo), e sim um casamento, "um mimetismo simbiótico entre exterior e interior, mas sem supressão da identidade específica e da singularidade recíproca da natureza e do homem" (WUNENBURGER, 2014, p. 85).

Na citação acima resvalamos de paisagem para natureza, embora esses dois termos não sejam sinônimos. Mesmo assim, assume-se aqui, deliberadamente, que a paisagem pressupõe a natureza. Natureza como o outro imprescindível para que se estabeleça uma relação de reciprocidade, na qual a identidade e a singularidade de cada um dos termos vem manifesta e preservada - a do mundo humano, aberto a possibilidades não determinadas previamente, e a da Terra, palavra que, neste contexto, vale por Natureza cuja essência, ao contrário da humana, é fechar-se em si (HEIDEGGER, 2010, p. 119-125).

O ponto a atingir é o seguinte: só a poesia pode dar ânimo, anima, alma, alento ao projeto de paisagismo (e não só de paisagismo), seja uma paisagem em prosa, isto é, prosaica, seja um poema paisagístico. Mas, ao abrirmos as comportas da poesia, o método e a técnica adquiridos serão levados pela enxurrada, água abaixo, e serão reformulados, remontados no percurso, até despontarem, a jusante, partícipes da mesma originalidade e indissociáveis da obra produzida.

Cabe transcrever o que diz Octavio Paz (2012, p. 25) sobre a técnica:

A técnica é procedimento e só vale na medida de sua eficácia, ou seja, na medida em que é um procedimento suscetível de aplicação repetida: seu valor dura até o momento em que surge um novo procedimento.
A técnica é repetição que se aperfeiçoa ou se degrada; é herança e mudança: o fuzil substitui o arco. A Eneida não substitui a Odisseia. Cada poema é um objeto único, criado por uma "técnica" que morre no momento exato da criação. A chamada "técnica poética" não é transmissível porque não é composta de receitas, e sim de invenções que só servem a seu criador.

A intransmissibilidade da "técnica poética" é extensível a outras formas de expressão, dentre as quais não haveria porque não incluir as paisagísticas. Os desafios que assim se colocam para o ensino de paisagismo são grandes: como "ensinar" disciplinarmente, ou seja, ter domínio sobre um método e uma técnica que acontecem sempre de um modo originário, novo, no produzir da própria obra? Como atingir o poético sem restringi-lo à genialidade e sem banalizar o termo?

Não se pretende e nem seria possível, aqui, chegar a respostas definitivas, mas, pelo menos, tocar nesses pontos parece ser fundamental para revigorar nossa disposição de ensinar e aprender esta "indisciplina" chamada paisagismo.

Quanto aos métodos e técnicas, é de se perguntar se não seria o caso de considerar as vantagens da heterodoxia ao invés de investirmos tudo em uma única via. Métodos e técnicas heterodoxos, da poesia à literatura, do teatro ao cinema, da fotografia à música, da culinária à dança, podem contribuir para o ensino de paisagismo. Não há porque subestimar os ganhos que poderiam advir do recurso a estes diferentes modos de "fazer", como nos ensina Certeau (1994, 2000), ou seja, de poetar.

Como vimos anteriormente com Octavio Paz, por mais distintas que sejam entre si, as formas de expressão têm algo em comum: todas são linguagem. Mas há algo que diferencia "um poema de um tratado em verso, um quadro de uma lâmina educativa, um móvel de uma escultura. Esse elemento distintivo é a poesia" (PAZ, 2012, p. 28-29). Não haveria porque não acrescentar a esses pares comparativos um novo par referente ao projeto de paisagismo. 
Mas qual o sentido em invocar a poesia hoje, depois de já ter sido questionada a aura da obra de arte e mesmo todo traço distintivo entre obra de arte e utensílio? O que se quer dizer quando se fala em poesia ou, mais especificamente, quando se reivindica uma poética na abordagem da paisagem como projeto?

Quanto a isso, talvez possa nos auxiliar o ensaio de Jean-Marc Besse intitulado "As cinco portas da paisagem", notadamente a quinta porta, qual seja, "A paisagem como projeto", no qual ele diz que "projetar é imaginar o real" (BESSE, 2009, p. 64). Tratase, segundo ele, de uma fórmula propositalmente ambígua:

Projetar a paisagem seria ao mesmo tempo colocá-la em imagem, ou representá-la (projeção), e imaginar o que ela poderia ser ou se tornar (projetação). Essa ambiguidade, ou circularidade, é constitutiva da própria noção de projeto no pensamento da paisagem. Ela leva em conta as duas dimensões contidas no ato de projetar: testemunhar, por um lado, e modificar, por outro (BESSE, 2009, p. 64).

Tal ambiguidade, continua Besse, também é encontrada nestes dois termos igualmente usados nos procedimentos de projeto: descrever e inventar. Descrever é fazer o inventário, e inventar é, ao mesmo tempo, "encontrar o que já estava ali (o arqueólogo inventa a peça que ele desenterra) e formular algo novo (uma ideia ou um objeto)" (BESSE, 2009, p. 64). O projeto de paisagismo seria, então, criar algo que já estava presente ali:

Trata-se, com efeito, de fabricar, de elaborar o que já está presente e que não se vê. É preciso construir para ver o que já está ali [...], é preciso traçar para saber o que se quer e o que se quer desenhar. A lógica do projeto é a lógica da obra. Seu critério não é a verdade (não há projetos verdadeiros e projetos falsos), mas antes a pertinência, ou a conveniência. [...] O projeto inventa um território ao representá-lo e ao descrevê-lo. Mas essa invenção é de uma natureza singular, porque o que é inventado já está, ao mesmo tempo, presente no território, mas como algo não visto e não sabido até então. A invenção revela o que já estava ali, ela libera e desvela, assim, um novo plano de realidade, mas essa realidade não seria vista se não fosse desenhada e pensada (BESSE, 2009, p. 64-65).

Destaquemos, da citação acima, estas duas frases: "a lógica do projeto é a lógica da obra" e "seu critério não é a verdade [...] mas antes a pertinência, ou a conveniência". Parece tratar-se da mesma "lógica" presente na origem da obra de arte, do modo como Heidegger $(2010)^{5}$ a concebe. Evidente que um projeto de paisagismo não é, necessariamente, uma obra de arte, nem o paisagista, um artista. Mas isso não significa que não haja similaridades de procedimentos e que não se possa explorá-las. Um paisagista, a depender da complexidade do projeto em que esteja envolvido, tem que se entender com distintas racionalidades e mover-se por diferentes territórios que a modernidade dissociou: "racionalidade instrumental [...]; racionalidade moral [...]; racionalidade estética [...]; racionalidade dialógica ou comunicacional, onde se instalam os quadros simbólicos" (BESSE, 2009, p. 67).

Como coordenar tanta complexidade é a grande questão. Já não se cogita atingir uma síntese e talvez isso nem seja necessário ou desejável. Admitindo que a experiência da paisagem seja, por excelência, a do pensamento aberto, Besse propõe uma "unidade sem síntese" ou, mais precisamente, "sem totalização" (BESSE, 2009 , p. 68). Tal postura, que não se limita ao âmbito do projeto, está longe de ser uma capitulação, uma desistência face à impossibilidade da síntese. Ao contrário, é uma atitude esperançosa que inverte o sentido das previsões, às vezes justificadamente pessimistas, da morte da paisagem, do desaparecimento do mundo. De fato, pondera Besse, um mundo no qual se pode representar o começo e o fim já não é um mundo habitado (no sentido mais amplo do termo), mas apenas um objeto que pode

5 Notadamente, em "A obra de a verdade" (p. 97 et seq.) e em "A verdade e a arte" (p. 145 et seq.). 
ser completamente apreendido pelo olhar, pelo pensamento e até mesmo percorrido em toda a sua extensão. O mundo, por ser humano, para ser humano, não pode se apresentar a nós como totalidade. Ele é inconcluso, e projetar seria, então, "desejar esse inacabamento" (BESSE, 2009, p. 69).

Uma unidade sem síntese, uma unidade inacabada, é a isto que aspiramos ou que podemos aspirar quando projetamos paisagisticamente, ou seja, quando criamos imagens paisagísticas. Não é diferente o que acontece com a imagem no poema:

[...] toda imagem aproxima ou acopla realidades opostas, indiferentes ou afastadas entre si. Isto é, submete a unidade à pluralidade do real. [...] Cada imagem [...] contém muitos significados opostos, ou díspares, que ela abrange ou reconcilia sem suprimir (PAZ, 2012, p. 104).

Conceitos e leis científicas também pretendem unificar. Contudo, lembra-nos Octavio Paz, diferentemente da poesia, a ciência tende a homogeneizar indivíduos e objetos reduzindo-os a abstrações. Já na poesia, os elementos da imagem são unificados sem perderem o seu caráter concreto e singular, e a imagem criada, quando diz que isto é também aquilo, ou seja, quando enuncia a identidade dos opostos, desafia o princípio da contradição (PAZ, 2012, p. 105) sem deixar de fazer todo sentido para nós.

Um exemplo de olhar poético me foi dado, tempos atrás, por um pesquisador ${ }^{6}$ que se dedicava, num inventário paisagístico, a adivinhar, sob o chão das ruas e entre quarteirões do bairro do Imirim, em São Paulo, um córrego oculto cuja nascente ele sabia estar localizada no interior de um cemitério, o Chora Menino. Ele poderia ter se referido àquela água enquanto composto molecular imprescindível à vida; ao comprometimento da potabilidade das nascentes no interior de um cemitério; poderia ter criticado o aprisionamento em tubos e a consequente indisponibilidade da água para outros usos; poderia ter apontado vantagens e desvantagens de sua exumação; ter discursado sobre o ciclo hidrológico. Preferiu falar sobre o alpendre de uma casa existente nos

6 Cf. Cabral (2015) arredores e que se abria, outrora, para o córrego hoje oculto; um alpendre agora "desfuncionalizado", sem sentido real e, no entanto, evocativo de vistas, "por cima do muro baixo", para o riacho, "com sua nascente vertendo água em abundância, uma água inesgotável, de som macio" (CABRAL, 2015). Uma água que já não existe para os olhos, que foi ressecada por camadas e camadas de pavimentos e que, no entanto, é inesgotável; uma nascente que mora num cemitério e que, a despeito disso, ou justamente por isso, está viva. O olhar vazio do alpendre está repleto de significados plurais, contraditórios, mas unificados numa imagem que nos leva a ver o que não está visível e a ouvir, entre as duras arestas das construções, a maciez do inaudível. 0 alpendre tornou-se imagem poética, símbolo que reúne, acolhe e revela uma água espectral. Ressuscita uma paisagem morta.

Não parece descabido que o ensino de paisagismo passe também por aí. Não poderá, contudo, deixar de precaver-se contra a tentação de entulhar o espaço com "imagens poéticas". Afinal, se é do mundo ser inconcluso e se a poesia diz essa inconclusão, vale atender a Clarice Lispector e proteger as entrelinhas...

\section{REFERÊNCIAS BIBLIOGRÁFICAS}

ASSUNTO, Rosario. Il paesaggio e l'estetica. 2. ed. Palermo: Novecento, 2005.

ASSUNTO, Rosario. Paisagem, Ambiente, Território: uma tentativa de clarificação conceptual. In: SERRÃO, Adriana Veríssimo (coord.). Filosofia da Paisagem: uma antologia. Lisboa: Centro de Filosofia da Universidade de Lisboa, 2011. p. 125-130.

BERQUE, Augustin (dir.). Cinq propositions pour une théorie du paysage. Seyssel: Champ Vallon, 1994.

BERQUE, Augustin. Les Raisons du paysage, de la Chine antique aux environnments de synthèse. Paris: Hazan, 1995.

BERQUE, Augustin. La pensée paysagère. Paris: Archibooks: Sautereau Éditeur, 2008.

BESSE, Jean-Marc. Ver a Terra: seis ensaios sobre a paisagem e a geografia. Tradução Vladimir Bartalini. São Paulo: Perspectiva, 2006.

BESSE, Jean-Marc. Le goût du monde: exercices de paysage. Arles: Actes Sud: ENSP, 2009. BONFADIO, Jacopo. Le Lettere. Ed. Aulo Greco, Roma. 1978.

CABRAL, Arthur Simões Caetano. Os córregos ocultos e seus resquícios nos espaços livres urbanos: os afluentes do córrego Mandaqui. Arquitextos, São Paulo, v. 15, n. 177.03, 2015 Disponível em: https://bit.ly/2megXMx. Acesso em: 27 set. 2019.

CARCHIA, Giani. Il paesaggio e l'enigma. In: GOLDIN, Marco (org.). Da Cézanne a Mondrian impressionismo, espressionismo, cubismo e il paesaggio del nuovo secolo in Europa. Conegliano: Linea d'ombra, 1999 
CERTEAU, Michel. A invenção do cotidiano: artes de fazer. Tradução Ephraim Alves. Petrópolis: Editora Vozes, 1994.

CERTEAU, Michel; GIARD, Luce; MAYOL, Pierre. A invenção do cotidiano: morar, cozinhar. 3. ed. Tradução Ephraim Alves, Lúcia Endlich Orth. Petrópolis: Vozes, 2000.

CLÉMENT, Gilles. Jardins, paysage et génie naturel. Domont: Collège de France: Fayard, 2012. CORBIN, Alain. O território do vazio: a praia e o imaginário ocidental. Tradução Paulo Neves. São Paulo: Companhia das Letras, 1989.

DARDEL, Eric. L'Homme et la Terre. Paris: CTHS, 1990.

EVANS, Susan Toby. Aztec Royal Pleasure Parks. Studies in the History of Gardens and Designed Landscapes, Abingdon-on-Thames, v. 20, n. 3, p. 206-228, 2000. DOI: 10.1080/14601176.2000.10435621

FERRIOLO, Massimo Venturi. Etiche del paesaggio: il progetto del mondo umano. Roma: Editori Riuniti, 2002.

HEIDEGGER, Martin. A origem da obra de arte. São Paulo: Edições 70, 2010.

HUNT, John Dixon. Greater perfections. London: Thames and Hudson, 2000.

PAZ, Octavio. O arco e a lira. Tradução Ari Roitman, Paulina Wacht. São Paulo: Cosac Naify, 2012.

PEREIRA, Virgínia Soares. Plínio e a sombra tutelar de Cícero. Ágora, Aveiro, n. 8, p. 79-104, 2006

PLíNIO, o Jovem. Letter to Gallus. In: JELLICOE, Geoffrey; JELLICOE, Susan. The landscape of man. New York: Thames and Hudson, 1995.

PRANDI, Reginaldo. Mitologia dos orixás. São Paulo: Companhia das Letras, 2008.

RILKE, Rainer Maria. Del paesaggio. In: D'ANGELO, Paolo (org.). Estetica e paesaggio. Bologna: II Mulino, 2009. p. 53-64.

RYCKMANS, Pierre. As anotações sobre pintura do Monge Abóbora-Amarga. Tradução de Carlos Matuck, Giliane Ingratta, Tai Hsuan An. Campinas: Editora da Unicamp, 2010.

WUNENBURGER, Jean-Jacques. Gaston Bachelard: poétique des images. Fano: Éditions Mimésis, 2014.

Vladimir Bartalini

Universidade de São Paulo (USP),Faculdade de Arquitetura e Urbanismo.

R. do Lago, 876, São Paulo, SP, Brasil, CEP 05508-080

Orcid: https://orcid.org/0000-0002-3412-0620

E-mail: bartalini@usp.br 